\title{
Research Article \\ Prevalence of nomophobia and its association with stress, anxiety and depression among students
}

\author{
Sureka V. ${ }^{1}$, Abeetha S. ${ }^{2}$, Suma S. ${ }^{2}$, Sadhana Subramanian ${ }^{3}$, Brinda S. ${ }^{2}$, Bhagyashree N. ${ }^{4}$, Ramya K. ${ }^{4}$, Ganesh M. ${ }^{5}$ \\ ${ }^{1}$ Professor, ${ }^{2}$ Assistant Professor, ${ }^{4}$ Associate Professor, ${ }^{5}$ Professor and Head, Department of Physiology, A.C.S. Medical \\ College and Hospital, Chennai, Tamil Nadu \\ ${ }^{3}$ Scientist B, ICMR - National Institute of Nutrition, Hyderabad, Telangana
}

(Received: May $2020 \quad$ Revised: October $2020 \quad$ Accepted: November 2020)

Corresponding author: Sureka Varalakshmi V.Email: surekaramesh.v@gmail.com

\begin{abstract}
Introduction and Aim: The change in human behaviour has created a social phobia wherein a human use either computers or any other electronic gadgets to defend himself from social contact. Nomophobia is fear of not having mobile phones and the stress associated with it. Increased use of mobile phones among students has changed the scenario and it is no more a luxury but a necessity. Social interaction has decreased and electronic gadgets have become the master. This has led to development of neuropsychological issues. The purpose of the study is to find out the prevalence of nomophobia among college students and to explore the association between nomophobia and stress, anxiety and depression.
\end{abstract}

Materials and Methods: Randomly selected 167 medical and dental students were given questionnaires to assess the prevalence of nomophobia. Separate questionnaires were given to assess stress, anxiety and depression.

Results: Results showed a wide prevalence of nomophobia (59\%) among students. 14\%, 29\%, 8\% of students were seen having severe/ extreme depression, anxiety and stress respectively.

Conclusion: Nomophobia was significantly associated with stress and depression $(\mathrm{P}<0.05)$. Students have to be periodically screened to identify stress, anxiety and depression and counselled about the constructive usage of mobile phones.

Keywords: Mobile phone use; stress; anxiety; depression

\section{INTRODUCTION}

$\mathrm{N}$ omophobia is a fear of not having mobile phones and psychological symptoms that arise due to fear of loneliness as virtual communication becomes indispensable part of our life. The use of smart phones is directly proportional to the applications that are available in the mobile phone. College students are trend setters for every new mobile phone that is introduced. Latest concept is No Mo phobia means no mobile phobia wherein a person feels highly insecure without their mobiles (1). A state of anxiety which affects concentration and behaviour (2). A study in Mumbai by Market Analysis and Consumer Research Organization (MACRO)on mobile phone usage reported that 58\% of the respondents could not manage even one day without a mobile phone (3). Nomophobics have mood swings and try to hold on to a mobile and have hallucinations of false mobile sounds and ring tones even while sleeping. Our study was planned to find out the prevalence of nomophobia among medical college students as adolescents are reported to handle mobile phones aggressively 24/7. Hostel students and students who travel long distances have more responsibility of being in touch with family and friends and gradually become addicted to their gadgets. Nomophobia is reported to get aggravated in people having stress and anxiety disorders. Not much research has gone into this field of nomophobia and its relation with stress and anxiety. This study was planned to understand the prevalence of nomophobia and to study if stress, anxiety and depression shows any association with nomophobia among college students.

\section{MATERIALS AND METHODS}

The present study was a cross-sectional study conducted among first year medical and dental college students. Study protocol was approved by the Institutional Ethics committee. 167 students were recruited for the study by systematic random sampling. Students already on treatment for depression and other nervous issues were not included. Recruited students were given information sheet about the study and informed consent was obtained from all the participants.

A pre-designed and pre-tested nomophobia questionnaire(4)similar to the one by Dr. Marcus L. Raines (5) was used to study mobile phone dependence among the study subjects. The questionnaire focusing on nomophobia had eight components: duration of having mobile phone with self; anxiety and stress experienced because of faulty connections; loss of mobile and battery discharge, reaction shown to phone ringing at inappropriate times; frequency of change of phone/sim cards and 
reactions because of inability of using the phone for a period of one week. Every question was compulsory and consisted of three options depicting maximum to minimum mobile phone association.

Data to assess stress was obtained using Cohen's stress scale (6) and Anxiety using GAD -7 questionnaire (7) and PHQ 9 for depression (8). Cohen's stress scale included ten questions on the students' behavior on handling unexpected situations, situations which made them highly irritable, very positive and confident. Each item is rated on a 5-point scale ranging from never to almost always. Positively worded items are reverse scored, and the ratings are summed, with higher scores indicating more perceived stress. Scores around 13 are considered average and 20 or higher are considered high stress, Anxiety questionnaire had seven questions regarding situations when they had trouble relaxing, or when they were worrying too much or feeling annoyed or feeling something awful might happen. Students were asked to mark scores on the frequency of experiencing these symptoms. The data were entered in excel and analysis done using SPSS software version 17.

\section{RESULTS}

Socio-demographic data indicated that the average age of participants was 21 years and the percentages of females and males were $76 \%$ and $24 \%$, respectively. Table 1 describes participants socio demographic characteristics.

In general, the symptoms (anxiety, trembling, perspiration, tachycardia, respiratory alterations, depression, panic, fear) or emotions (comfort, agitation, disorientation, dependence, rejection, low self-esteem, loneliness, insecurity) due to not having access to a mobile phone were significantly different between the participants $\left(\chi^{2}=13,314\right.$, df $=1, \mathrm{p}<$ $0.001)$.

Table 1: Socio- demographic characteristics of the participants

\begin{tabular}{|c|c|}
\hline Characteristics & Number (\%) \\
\hline Age in years & \\
\hline 18 & $98(58.7)$ \\
\hline 19 & $56(33.5)$ \\
\hline 20 & $12(07.2)$ \\
\hline 21 & $1(0.6)$ \\
\hline Gender & $36(21.6)$ \\
\hline Male & $131(78.4)$ \\
\hline Female &
\end{tabular}

Socio-demographic characteristics of 167 study participants (Table 1), shows majority $(58.7 \%)$ were 18 years of age, and 131 (78.4\%) participants were females.

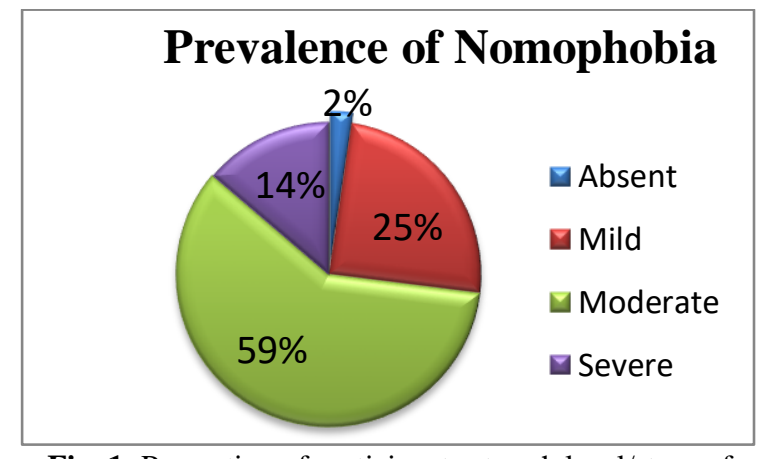

Fig. 1: Proportion of participants at each level/stage of nomophobia

Proportion of participants in each level/stage of nomophobia (Fig. 1) shows, majority (59\%) were having moderate nomophobia. $2 \%$ of participants had no symptoms of nomophobia.

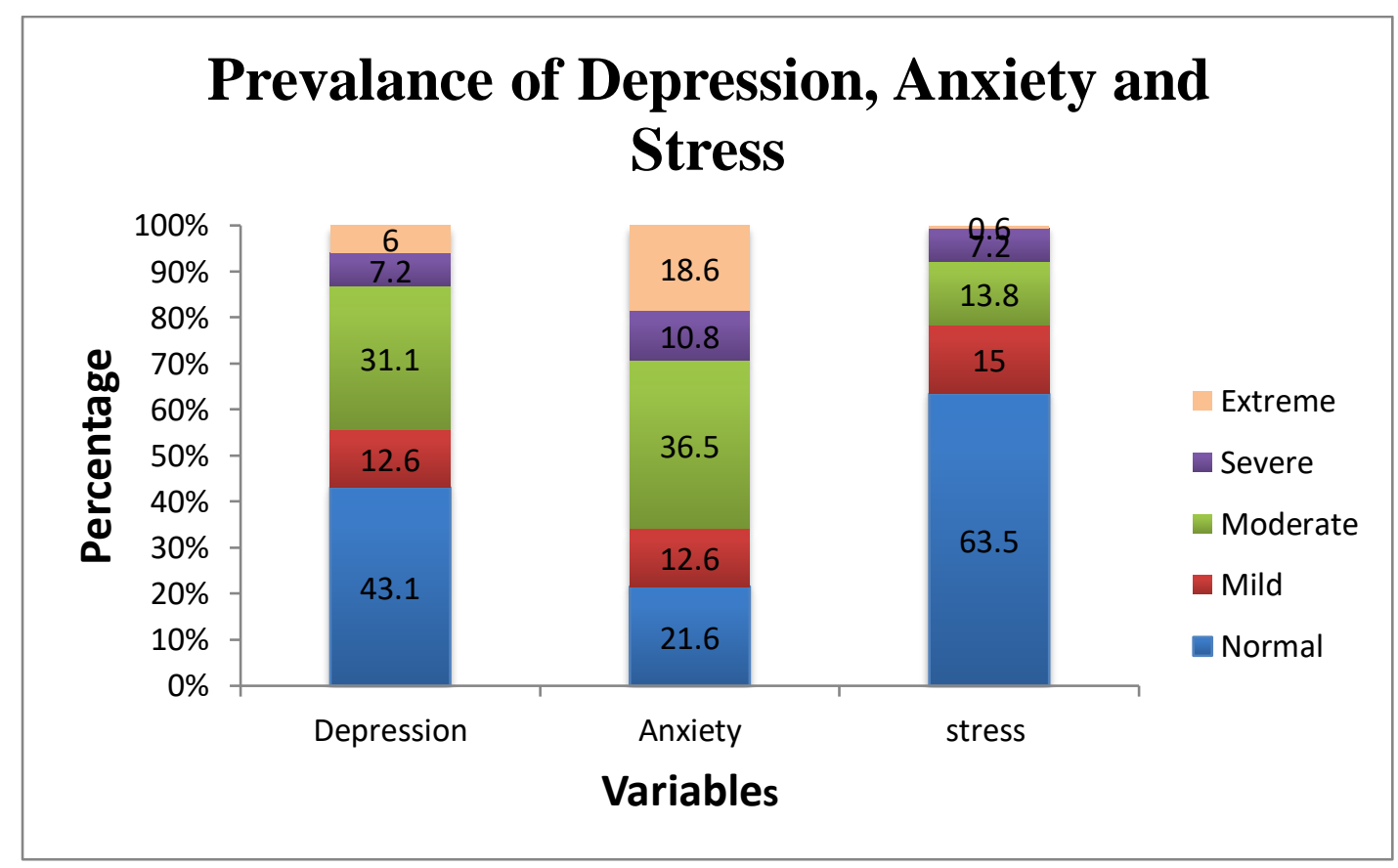

Fig. 2: Proportion of participantsin each stage/level of depression, anxiety and stress among the students. 
Proportion of participants in each stage/level of depression, anxiety and stress among the students (Fig. 2) shows, 14\%, 29\%, 8\% were having severe/ extreme depression, anxiety and stress respectively. $36.5 \%$ and $31.1 \%$ showed moderate anxiety and depression respectively.

Table 2: Association of depression with nomophobia

\begin{tabular}{|c|c|c|c|c|c|}
\hline \multirow{2}{*}{ Depression* } & \multirow{2}{*}{$\begin{array}{c}\text { Total number of } \\
\text { participants }(\mathbf{n}\end{array}$} & \multicolumn{2}{|c|}{ Nomophobia (n \%) } & \multirow{2}{*}{$\begin{array}{c}\text { Prevalence ratio } \\
\text { (95\%) CI) }\end{array}$} & \multirow{2}{*}{ P-value } \\
\cline { 3 - 4 } & Yes & No & & \\
\hline Yes & $74(45)$ & $60(81)$ & $14(19)$ & $1.22(1.01-1.45)$ & 0.03 \\
\hline No & $93(55)$ & $62(67)$ & $31(33)$ & 1 & \\
\hline Total & $\mathbf{1 6 7 ( 1 0 0 )}$ & $\mathbf{1 2 2}(\mathbf{7 3})$ & $\mathbf{4 5}(\mathbf{2 7})$ & & \\
\hline
\end{tabular}

*Participants in moderate, severe and extreme categories were considered as depressed.

Association of depression with nomophobia among 167 study participants (Table 2) shows, the prevalence of nomophobia was $1.22(1.01-1.45)$ times more likely among people with depression as compared to those who were not depressed with a P-value of 0.03 which was statistically significant.

Table 3: Association of stress with nomophobia among the students

\begin{tabular}{|c|c|c|c|c|c|}
\hline \multirow{2}{*}{ Stress* } & \multirow{2}{*}{$\begin{array}{c}\text { Total number of } \\
\text { participants (n \%) }\end{array}$} & \multicolumn{2}{|c|}{ Nomophobia (n \%) } & \multirow{2}{*}{$\begin{array}{c}\text { Prevalence Ratio } \\
\text { (95\% CI) }\end{array}$} & \multirow{2}{*}{ P-value } \\
\cline { 3 - 4 } & Yes & No & $1.24(1.04-1.47)$ & 0.04 \\
\hline Yes & $36(45)$ & $31(86)$ & $5(14)$ & 1 & \\
\hline No & $131(55)$ & $91(70)$ & $40(30)$ & & \\
\hline Total & $\mathbf{1 6 7 ( 1 0 0 )}$ & $\mathbf{1 2 2}(\mathbf{7 3 )}$ & $\mathbf{4 5 ( 2 7 )}$ & & \\
\hline
\end{tabular}

*Participants in moderate, severe and extreme categories were considered as stressed.

Association of stress with nomophobia among 167 study participants (Table 3 ) shows, the prevalence of nomophobia was $1.24(1.04-1.47)$ times more likely among people with stress as compared to those who were not stressed with a P-value of 0.04 which was statistically significant.

Table 4: Association of anxiety with nomophobia

\begin{tabular}{|c|c|c|c|c|c|}
\hline \multirow{2}{*}{ Anxiety* } & \multirow{2}{*}{$\begin{array}{c}\text { Total number of } \\
\text { participants }(\mathbf{n}\end{array}$} & \multicolumn{2}{|c|}{ Nomophobia (n \%) } & \multirow{2}{*}{$\begin{array}{c}\text { Prevalence Ratio } \\
\text { (95\% CI) }\end{array}$} & \multirow{2}{*}{ P-value } \\
\cline { 3 - 4 } & $\mathbf{\%})$ & Yes & No & & \\
\hline Yes & $110(45)$ & $84(76)$ & $26(24)$ & $1.14(0.92-1.41)$ & 0.18 \\
\hline No & $57(55)$ & $38(67)$ & $19(33)$ & 1 & \\
\hline Total & $\mathbf{1 6 7 ( 1 0 0 )}$ & $\mathbf{1 2 2}(\mathbf{7 3})$ & $\mathbf{4 5}(\mathbf{2 7})$ & & \\
\hline
\end{tabular}

*Participants in moderate, severe and extreme categories were considered as anxious.

Association of anxiety with nomophobia (Table 4) shows the prevalence of nomophobia was $1.14(0.92-$ 1.41) times more likely among people who were anxious as compared to those who were not. However, the association was statistically insignificantwith a Pvalue of 0.18 .

\section{DISCUSSION}

Mobile phones have become an integral part of our life and this study tries to correlate the interaction of modern technology with common psychology. The mobile phone may be working as a "phobic partner" for some patients. It is like a double edged sword. People with panic disorders show more emotional instability than normal (9). Though nomophobia is not yet included in Diagnostic manual of statistical and mental disorders -DSM (10) existing data show that this disorder is growing enormously. Our study also shows a similar pattern with wide prevalence of nomophobia among college students. Studies have reported that no significant association was seen between mobile phone users based on gender, year of study and place of stay (11).Usage of mobile phones among students (12) is generally based on the advanced smart phone gadget and its multi-tasking features. Data is available where students from secondary schools also (13) spent longer time on mobile phones. Reasons for prevalent use could be due to the fact that all smart phones have resolution bigger than a normal camera and use of smart phones in photography or for recording videos for all occasions has become easier and user friendly. Availability of Wi-Fi in classrooms and libraries have made recording of lectures easier and downloading huge data from books without having to carry a textbook.

Overuse of wireless mobile devices (WMDs) may be associated with a form of psychological dependency, of which a prominent feature may be anxiety arising from separation from these devices. Our results also show significant association of Nomophobia with stress and anxiety. It is difficult to conclude if anxiety leads to Nomophobia or is it overuse of mobile phone that is causing anxiety and depression (14). Withdrawal symptoms of mobile phones aggravated the problem. Our results show that students have increased stress due to non-use of mobile phones 
which leads to depression and anxiety. Chronic mobile phoners have also reported very low quality of sleep leading to mental health issues (15). Studies done among youth have reported wide prevalence of mental health issues along with physical discomfort such as headache and constant burning and itching of eyes leading to stress (16). College students, who are among the most avid consumers of WMDs, become highly susceptible to the negative effects of WMD overuse (17). Our previous studies (18) done on students also showed that stress and depression had a significant association with cognitive failure.

\section{CONCLUSION}

As wide prevalence of nomophobia can lead to anxiety, stress and depression counselling the students on smart and productive ways of using mobile phones along with screening for these disorders will help the teenagers face the academic and social pressures. Face to face interaction with minimum use of mobile phones must be encouraged. Increased awareness is needed among the youth regarding nomophobia. Standardized measures for identification and appropriate psycho-behavioural therapy for those seeking help might also help to alleviate the problem.

\section{Limitations}

The study was conducted only among first year students. Similar study is being planned on senior students to assess the effect of mobile phone usage on their physical and mental health.

\section{CONFLICT OF INTEREST}

Authors declare no conflict of interest.

\section{REFERENCES}

1. King, A.L.S., Valença, A. M., Silva, A. C., Baczynski, T., Carvalho, M. R., Nardi, A. E.Nomophobia: Dependency on virtual environments or social phobia? Computers in Human Behavior. 2013; 29: 140-144.

2. Yildirim, C., Correia, A. P. Exploring the dimensions of nomophobia: Development and validation of a self-reported questionnaire. Computers in Human Behavior. 2015; 49: 130137.

3. Macro - market analysis and consumer research organization. A report on study of mobile phone usage among the teenagers and youth in Mumbai. Apr-May 2004.

4. Dixit, S., Shukla, H., Bhagwat, A. K., Bindal, A., Goyal, A., Zaidi, A. K., Shrivastava, A. Study to Evaluate Mobile Phone Dependence Among Students of a Medical College and Associated Hospital of Central India. Ind J Community Med. 2010; 35(2): 339-341.

5. Raines, M. L. An introduction to Nomophobia (Learn about Nomophobia) Available from: http://www.nomophobic.co.uk/.

6. Cohen, S., Deverts, J. D., Miller, G. E. Psychological stress and disease. JAMA. 2007; 298: 1685-1687.

7. Spitzer, R. L., Kroenke, K., Williams, J. B., Lowe, B. A brief measure for assessing generalized anxiety disorder: The GAD-7. Arch Intern Med. 2006; 166: 1092-1097.

8. Kroenke, K., Spitzer, R. L., Williams, J. B. The PHQ-9: validity of a brief depression severity measure. J Gen Intern Med. 2001; 16(9): 606-613.
9. King, A.L.S., Valença, A. M., Silva, A. C., Sancassiani, F., Machado, S., Nardi, A. E. Nomophobia- Impact of Cell Phone Use Interfering with Symptoms and Emotions of Individuals with Panic Disorder Compared with a Control Group. Clin Pract Epidemiol Ment Health. 2014; 10: 28-35.

10. Diagnostic and statistical manual of mental disorders. 4th ed. Text-Revision. Washington. DC: American Psychiatric Association; American Psychiatric Association. 2000; 393444.

11. Pavithra, M. B., Suwarna, M., Murthy, M.T.S. A study on nomophobia. Mobile phone dependence, among students of a medical college in Bangalore. Natl J Community Med. 2015; 6: 340-344.

12. Yildirim, C., Correia, A. P. Understanding Nomophobia: A Modern Age Phobia Among College Students. In: Zaphiris P., Ioannou A. (eds) Learning and Collaboration Technologies. LCT 2015. Lecture Notes in Computer Science. 2015; 9192: 724-735.

13. Nikhita, C. S., Jadhav, P. R., Ajinkya, S. A. Prevalence of mobile phone dependence in secondary school adolescents. J Clin Diagn Res. 2015; 9(11): VC06-VC09.

14. Bhattacharya, S., Bashar, M. A., Srivastava, A., Singh, A. NOMOPHOBIA: NO MobilePhonePhoBIA. J Family Med Prim Care. 2019; 8(4): 1297-1300.

15. Papaconstantinou, E., Bartfay, W. J., Bartfay, E. Smartphone use, sleep quality and quantity, and mental health outcomes in a university population. Sleep Medicine. 2017; 40: e251.

16. Borkotoky, C., Saikia, J. A study on prevalence of mobile phone dependence among youth of Jorhat district. Ind $\mathbf{J}$ of Health and Wellbeing. 2019; 10 (7): 246- 248.

17. Singh, B., Gupta, R., Garg, R. Mobile phones; a boon or bane for mankind? - Behavior of medical students. Intl $\mathrm{J}$ of Innovative Research and Dev. 2013; 2(4): 196-205.

18. Varalakshmi, S., Karthick, S., JeevaJothy, S. Prevalence of elevated blood pressure, stress, and anxiety and its association with cognitive failure among medical students A cross-sectional study. Natl J Physiol Pharm Pharmacol. 2020; 10 (3): 232-235. 